(C) 2019 by the Arizona Board of Regents on behalf of the University of Arizona. This is an Open Access article, distributed under the terms of the Creative Commons Attribution licence (http://creativecommons. org/licenses/by-nc-sa/4.0/), which permits unrestricted re-use, distribution, and reproduction in any medium, provided the original work is properly cited.

\title{
A PRELIMINARY ION SOURCE BACKGROUND STUDY AT LALONDE AMS
}

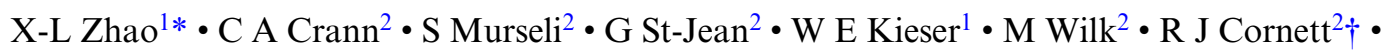 I D Clark ${ }^{2}$}

\author{
${ }^{1}$ Department of Physics, A. E. Lalonde AMS Laboratory, University of Ottawa, 25 Templeton St., Ottawa, ON, K1N \\ $6 \mathrm{~N} 5$, Canada \\ ${ }^{2}$ Department of Earth and Environmental Sciences, A. E. Lalonde AMS Laboratory, University of Ottawa, 25 \\ Templeton St., Ottawa, ON, K1N 6N5, Canada
}

\begin{abstract}
Observation of the ion source generated background has been an area of focus during our routine analytical work. It is noted that the results of very-low-ratio samples are dependent upon the particular procedures for measurement using the present-day $\mathrm{Cs}^{+}$sputter ion sources. When measured without excessive $\mathrm{Cs}^{+}$fluxes and without interleafing with other higher-ratio samples and references, the accelerator mass spectrometry (AMS) sensitivity can be somewhat improved. In some cases, it appears possible to assess old radiocarbon $\left({ }^{14} \mathrm{C}\right)$ samples to beyond the long-standing $60 \mathrm{kyr}$ limit. A number of observational studies are made for the sole purpose of minimizing the final contamination to the rare isotopes that is generated within the ion source.
\end{abstract}

KEYWORDS: critical surfaces surrounding the ionizer and target (CSSIT), ion source memory effects, old carbon project (OCP).

\section{BACKGROUND AND MOTIVATION}

When accelerator mass spectrometry (AMS) was first developed for radiocarbon $\left({ }^{14} \mathrm{C}\right)$ dating, it was expected to make two major advances over the traditional beta-counting method: (1) a thousand-fold reduction in sample sizes, and (2) an extension of the dating range to beyond $60 \mathrm{kyr} \mathrm{BP}$ (Schmidt et al. 1987). While the first objective was easily achieved, the second remains unfulfilled for samples that must be chemically processed, despite the many in-depth studies (e.g., Beukens 1993) on the sources that contribute to the background in AMS measurement. The motivation for this subject was inherited from the IsoTrace investigation for the "Old Carbon Project" (OCP) (Beukens et al. 2004; Litherland et al. 2005). The OCP was initiated by requests to search and certify the lowest possible ${ }^{14} \mathrm{C}$-containing organic materials for the construction of low-background solar-neutrino detectors. At IsoTrace, the studies were more focused on the assessment of the ultimate E/q and $\mathrm{EM} / \mathrm{q}^{2}$ background for ${ }^{14} \mathrm{C}$ measurement, and it was concluded that the system used then had an abundance sensitivity of ${ }^{14} \mathrm{C} /{ }^{12} \mathrm{C} \sim 10^{-18}$ (Beukens et al. 2004). Now, using the much-improved system at Lalonde AMS (Kieser et al. 2015), this intrinsic performance could be expected to be further enhanced, perhaps approaching the ultimate goal of $10^{-21}$ (Litherland et al. 2005). However, ${ }^{14} \mathrm{C}$ ages defined by the ${ }^{14} \mathrm{C} /{ }^{12} \mathrm{C}$ ratios in the range of $10^{-18}-10^{-21}(110-170 \mathrm{kyr})$ have been unattainable. Recently, a similar request was received to assess the ages of certain organic materials for the $\mathrm{SNO}+$ project, the deep underground detector for neutrino-less double beta decay searches, located $2 \mathrm{~km}$ below the surface in Sudbury, Canada (Andringa et al. 2016). It provided an opportunity for investigating the measurement limit, such as the sources of carbon that are not from the sample itself. Some limited observational studies on such topics are made and described here, for the sole purpose of pushing the lowest isotope ratio limit for samples

\footnotetext{
†Deceased.

*Corresponding author. Email: xiaolei.zhao@uottawa.ca.
} 
with no material limit. For ${ }^{14} \mathrm{C}$, the focus is only on those background sources that are introduced after the beginning of the graphitization process.

\section{HYPOTHESIS}

These studies are based on the hypothesis that there could be two major origins of background carbon in these later steps, as follows:

\section{Step 1: Carbon contamination on the surface of a pressed target}

Fresh targets all carry non-sample carbon in them, some loosely adsorbed on the surface (e.g. atmospheric $\mathrm{CO}_{2}$, aerosols), some more tightly bound (e.g. deep diffusion, chemical association), and others originally existing in the catalyst as compounds (e.g. iron carbide). These have been studied before (e.g. Santos et al. 2007; Paul et al. 2016). Here, a further example is presented to display the release of the different types of non-sample carbon by separate time constants in the ${ }^{13} \mathrm{C}^{+3}$ and ${ }^{12} \mathrm{C}^{+3}$ currents measured from Fe-only blanks. The Fe-only blanks have gone through the same graphitization preconditioning routine as the iron used for the samples $\left(700 \mathrm{mBar}_{2}\right.$ at $520^{\circ} \mathrm{C}$ for $20 \mathrm{~min}, 700 \mathrm{mBar}_{2}$ at $520^{\circ} \mathrm{C}$ for 30 min, pump $1 \mathrm{hr}$, fill to 1 bar with $\mathrm{Ar}$, cap and store), except that no $\mathrm{CO}_{2}$ is let in the graphitization reactor. To obtain an accurate measurement, the lowest available range of $100 \mathrm{nA}$ (full scale) must be used for both ${ }^{13} \mathrm{C}^{+3}$ and ${ }^{12} \mathrm{C}^{+3}$. In addition, these currents (measured in the Faraday cups) must be corrected for the base electronic noise (including dark current from the accelerator terminal alone) that can be determined with the ion source exit gate valve closed. Figure 1 presents the results of one such special measurement. A mini-batch of three new Fe-only blanks (5 mg, -325 mesh, Alfa Aesar, same quantity used for each graphite sample described in this work) was first measured before a long regular sample batch. After the long batch run, another mini-batch of three new Fe-only blanks was measured. From these Fe-only blanks, the carbon beams measured initially are presumably mostly due to adsorbed carbon from the atmosphere.

Adsorption is inevitable, but carbon adsorbed onto the pressed sample and target holder surfaces is rapidly desorbed by the $\mathrm{Cs}^{+}$sputtering. So, this should not be too serious a problem provided that the graphite targets are pressed no more than a week prior to installation into the ion source and the initial few blocks of measurement are discarded, if necessary. However, in our case it takes $\geq 30$ blocks ( $\geq 15 \mathrm{~min}$ ) of measurements to exhaust the more tightly bound surface carbon (Figure 1). This is a more important background carbon, as it is no different to that of a "small sample." The carbon mass of this smallest "sample" is difficult to estimate; but assuming that this portion of non-sample carbon is also mostly introduced after the target is pressed, similar to that of top surface adsorption, it can still be discarded by $\mathrm{Cs}^{+}$sputter cleaning over an extended length of time. However, there are still the long-lasting carbon beams at some base levels, which are partly due to the catalyst-included carbon and partly those originating in the ion source. These are, of course, not macroscopic quantities, but may still be important for measuring samples at the age limit. In our case about $60 \mathrm{~min}$ are spent to measure each target, from which duration an average carbon mass on the order of $0.2 \mu \mathrm{gC}$ can be estimated for the smallest "sample" as represented by the Fe-only blanks. This estimation is based on the average ${ }^{12} \mathrm{C}^{+3}$ current $(\sim 10 \mathrm{nA})$ of the Fe-only blanks measured within the $60 \mathrm{~min}$, in comparison to those $(\sim 10 \mu \mathrm{A})$ of graphite loaded targets containing $200 \mu \mathrm{gC}$, assuming that the current and mass are more or less linearly correlated in this low carbon mass range. 

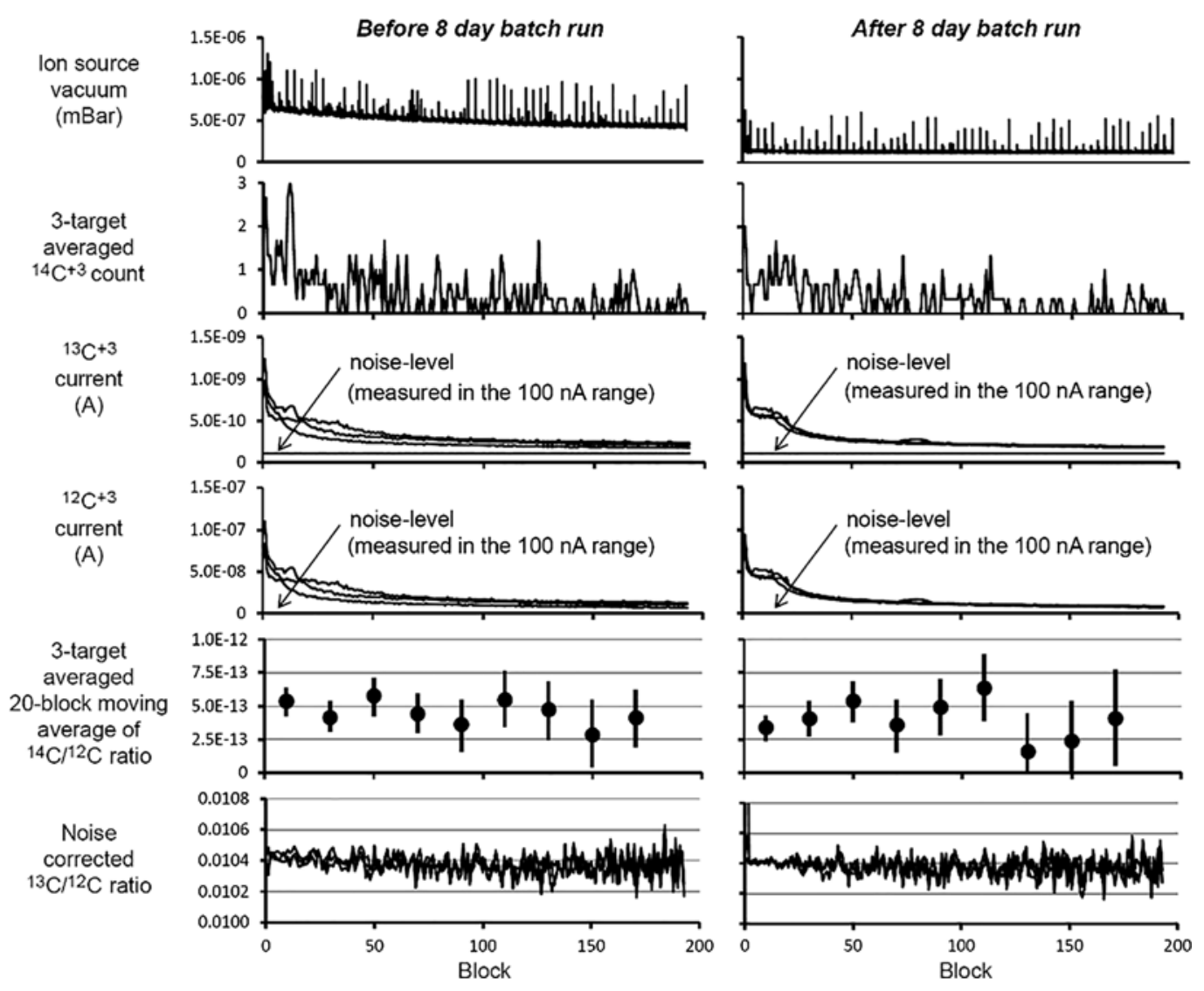

Figure 1 Typical results of 5-mg Fe-only blanks before and after a long regular batch run. Measurement is recorded in the unit of block, where one block represents 30 -sec data acquisition using $92 \mathrm{~Hz}$ fast sequential injection. 10 blocks are measured on a target during each pass; nearly 20 passes are measured for all targets. For this and all measurements in this work, $2.5 \mathrm{MV}$ terminal voltage is used and is stabilized by the generating voltmeter only.

Considering the purity of the Fe used for the graphitization, this $\sim 0.2 \mu \mathrm{gC}$ quantity must be gained elsewhere, and in stages after the $\mathrm{CO}_{2}$ production. Furthermore, limited preliminary observations also suggest that when different amounts of $\mathrm{Fe}$ (or $\mathrm{Cs}^{+}$flux) are used in the Fe-only blanks, there are differences in the average carbon currents measured, and the differences appear more than what the different Fe masses can explain. Considering these observations and the fact that all ion sources require cleaning after a period of use, it is reasonable to suggest that when the surface adsorbed and surface-bound sources are removed, the carbon beams continuing to be produced from the Fe-only blanks are from the ion source itself as described below.

\section{Step 2: Carbon contamination in the ion source during measurement}

The ion source produced background is well known to exist at some levels using the now standard Middleton-type $\mathrm{Cs}^{+}$sputter sources, but the details are not well understood. It is reasonable to hypothesize that there are two major sources of background carbon inside such an ion source: one being the residual hydrocarbon vapors from vacuum system components and the other being materials deposited on the critical surfaces surrounding the 
ionizer and target (CSSIT) that collectively come from all the carbon containing targets that have been sputtered. Which contribution is more important and how these seemingly neverending, base-level carbon beams are generated need to be determined.

A carbon containing molecule in the vacuum can randomly impinge onto the target, where catalytic reactions could take place resulting in carbon reduced onto the target surface, since it is heated by the $\mathrm{keV} \mathrm{Cs}{ }^{+}$sputter beam. This must make up a very basic part of the ion source produced background, as the process is similar to what occurs from $\mathrm{CO}_{2}$ gas samples. In a sense, the ion source can always act like a graphite reactor, especially when a target containing catalyst is sputtered. The level of this part of the background naturally depends on the partial pressures of carbon-containing vapors in the vacuum. Figure 1 shows that, when the ion source vacuum is better than $1 \times 10^{-6} \mathrm{mBar}$, there are no longer differences to the final base-level carbon beams produced from the Fe-only blanks. It is also interesting to note that a long multi-day batch run with many contemporary level targets included, also did not make a difference to the amount of ${ }^{14} \mathrm{C}^{+3}$ counts collected from the two separate mini-batches of three Fe-only blanks, which were measured only by themselves on either side of the long regular batch run. This suggests that, at our normal $\mathrm{Cs}^{+}$flux of $\leq 0.3 \mathrm{~mA}$ (estimated very roughly from the complete usage of a 5-g Cs refill) producing $\leq 40 \mu \mathrm{A}{ }^{12} \mathrm{C}^{-}$, changes in the memory effects at whatever levels they may have built up, are not readily observed after vacuum becomes sufficiently good. It is thus tentatively hypothesized that the final memory effects are not generated via carbon containing vapors present in vacuum, but by a different mechanism that somehow recycles the materials of all the targets sputtered during an ongoing batch run.

To elaborate on this, it has been noted that there is a recycling process going on between the ionizer and targets that could amplify the memory effects. This clue was obtained during a study of $\mathrm{CsF}_{2}^{-}$current production using a typical high intensity $\mathrm{Cs}^{+}$sputter source, but with the Cs reservoir not mounted (Zhao et al. 2016). It was found that even without the Cs reservoir mounted, there still could be no shortage of sputter ions that actually originate from the sample materials themselves. Although the drastic effects described by Zhao et al. (2016) are mainly due to the high volatility of the $\mathrm{PbF}_{2}$ targets used, there is no reason to completely rule out similar phenomena for other sample materials. That is, part of the evaporated, sublimed, and sputtered neutral atoms or molecules from the target can be softly deposited, chemically bound or even implanted onto the ionizer and surrounding surfaces. Soft-landed neutrals may have relatively short residence time on a hot ionizer surface, but the sputtered neutrals are the most troublesome as they have energies with probability peaking at few $\mathrm{eV}$ but also extending to the hundreds of $\mathrm{eV}$ level. These are large enough energies to activate chemical reactions onto the surfaces where the incoming neutrals become chemically bound to the surface. Once chemically bound, the deposited neutrals would stay longer and aggregate on, or diffuse into, the surface as if they are implanted. The dynamic details on the ionizer surface are unknown, but it can be argued that the bound or "trapped" incoming atoms can still be sputtered or desorbed off the ionizer surface by incoming atoms having $>\mathrm{eV}$ energies, since the typical atom bonding strength to a metal surface is a few $\mathrm{eV}$ at most. For example, according to the CRC Handbook of Chemistry and Physics, most C-metal bond strengths are 4-6 eV, about half of the strongest $\mathrm{C}-\mathrm{O}$ bond. Thus, a combination of long residence and re-disturbance for deposited neutrals on the ionizer surface naturally makes up a source for memory background. Worse still, if some of the released neutrals become ionized upon leaving the hot ionizer surface, either as atomic ions or as part of molecular ions, they would be 
directly returned as focused sputter ions to implant into the targets that follow. Carbon and Cs can form clusters, as the ready formation of their negative cluster ions are described by Middleton and Klein (1997). At least, the hypothetical possibility of forming similar positive cluster ions cannot be expected to be nonexistent, although they remain to be experimentally confirmed in future studies. The continued reasoning in this work is based on the assumption that there is a probability for such recycling phenomena, although for refractory elements such as carbon, the recycling phenomena are expected to be far less probable via fast atomic neutrals than with volatile molecules.

Similarly, the surfaces surrounding the target and ionizer are inevitably coated with materials accumulated from all targets previously sputtered. These materials can re-evaporate or be ejected by disturbances such as impacts from unfocused ions or neutrals at any time, thus having a chance to hit the target or ionizer again. Since the ionizer has a large surface area, the recycled sputtering phenomenon described can act as an amplifier, which enhances the ion source memory effects. According to this analysis, once the target outgassing phase is completed and a sufficiently good vacuum is reached, the carbon containing materials that have accumulated on the ionizer and the critical surfaces surrounding that ionizer and target (CSSIT), can become a relatively more important source of background carbon responsible for the ion source memory effects.

Therefore, it is hypothetically reasoned that (1) the final measurement background is at least partly due to the recycled sputter ions originating from previous samples via prolonged stays on the ionizer and CSSIT; and (2) such background should be, at least to some extent, correctable via frequent measurement of suitable blanks that do not contain the element of interest being measured. In the case of ${ }^{14} \mathrm{C}$ measurement, the suitable blanks are thought to be the Fe-only blanks that are prepared in the same way as graphite samples without $\mathrm{CO}_{2}$ admitted; in the case of ${ }^{129} \mathrm{I}$ measurement, they are the pure $\mathrm{Nb}$-only blanks, made of the same $\mathrm{Nb}$ powder used as a conducting binder for the AgI sample material. Consequently, two ion source operating conditions are expected to be helpful in reducing the measurement background level: (1) the use of $\mathrm{Cs}^{+}$sputter beams with suitable intensities where the rate of CSSIT coating due to target material removal by mere thermal power is not excessive, and where there are also fewer unfocused ions and neutrals disturbing CSSIT; and (2) the exclusion of higher activity samples, such as the usual standard targets (Ox-I, Ox-II, etc.) during the measurement of very-low level samples, should result in lower ratios (older ages) to be measured. Both of these were in fact already reported or implied in some of the earlier studies (e.g. Taylor and Southon 2007; Pavetich et al. 2014; Vockenhuber et al. 2015). Further observations described below support these views for AMS in general, in spite of the huge differences for different elements.

\section{NECESSITY OF USING SUITABLE Cs ${ }^{+}$SPUTTER BEAMS IN SOME CASES}

The background dependence on the $\mathrm{Cs}^{+}$beam intensity is clearly more obvious and readily shown with the measurement of ${ }^{129} \mathrm{I}$ as an example, due to the relatively high volatility of iodine upon $\mathrm{Cs}^{+}$sputtering. With the high resolution/bending-power of the Lalonde AMS system, the ultimate sensitivity of ${ }^{129} \mathrm{I} /{ }^{127} \mathrm{I}$ has long been felt to be limited only by the operating conditions of the ion source. It is very important to strive for the lowest possible ${ }^{129} \mathrm{I}$ background for samples associated with naturally occurring ${ }^{129} \mathrm{I}$, such as ultra-deep mine brines; the results of these samples are frequently near the levels of process blanks. To this end, two changes have been implemented in this laboratory. 
${ }^{129}+2$ energy spectrum of $\mathrm{Nb}$ blank taken at 4 different $\mathrm{Ar}$ stripper pressures

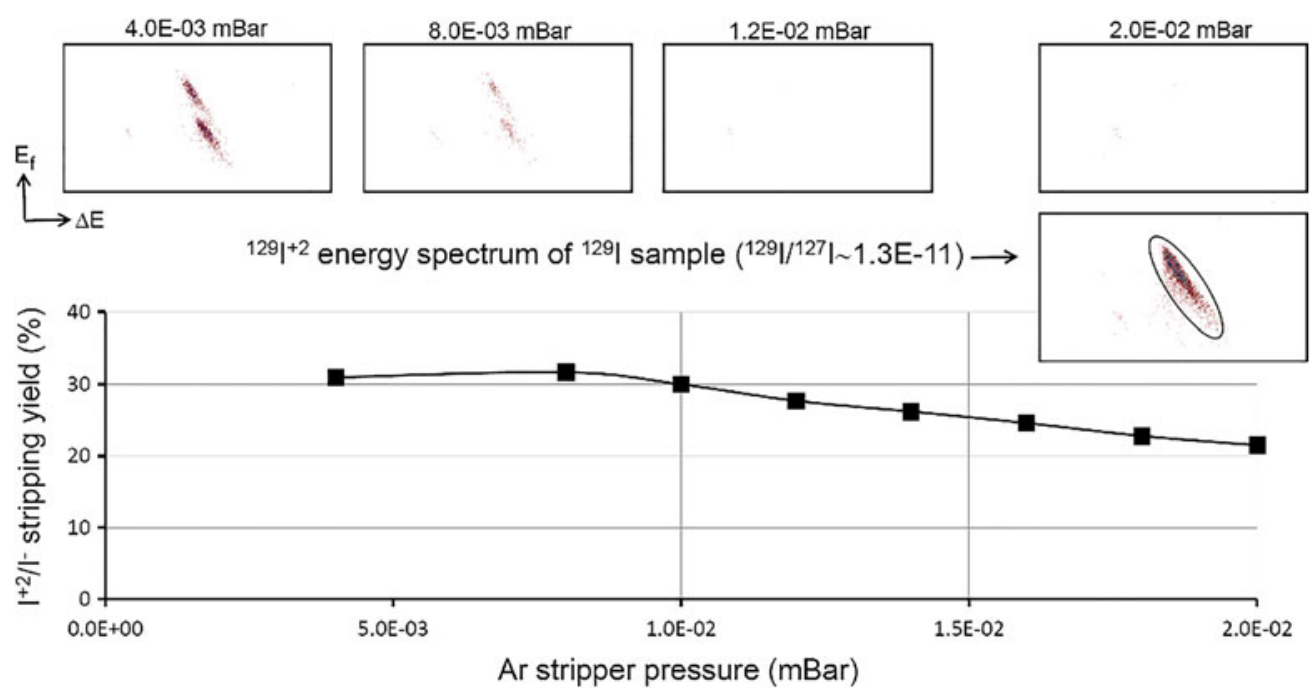

Figure 2 Stripper pressure dependence of $\mathrm{I}^{+2}$ yield, and the ${ }^{129} \mathrm{I}^{+2}$ spectra from an Nb-only blank and an AgI reference $\left({ }^{129} \mathrm{I} /{ }^{127} \mathrm{I} \sim 1.3 \times 10^{-11}\right)$.

First, following the successful demonstration of ${ }^{129} \mathrm{I}^{+2}$ detection by Vockenhuber et al. (2015), our selection of ${ }^{129} \mathrm{I}^{+3}$ (Kieser et al. 2015) has been switched to ${ }^{129} \mathrm{I}^{+2}$. With $2.5 \mathrm{MV}$ terminal voltage and $2.0 \times 10^{-2} \mathrm{mBar}$ Ar stripper pressure, a $20 \%$ transmission through the accelerator is obtained; where the doubly charged interfering molecules are sufficiently eliminated as shown from an Nb-only blank target (Figure 2). Compared to the earlier choice of detecting ${ }^{129} \mathrm{I}^{+3}$, the measurement efficiency is improved, and the occasional interference from strong ${ }^{86} \mathrm{Sr}^{+2}$ fluxes for measuring ${ }^{129} \mathrm{I}^{+3}$ is avoided.

Second, the critical $\mathrm{Cs}^{+}$flux that must be used for measuring very-low level ${ }^{129} \mathrm{I}$ samples was determined. Three increasing $\mathrm{Cs}^{+}$fluxes (Figure 3), in order from low to high, were used to measure six replicate groups of the $\mathrm{Nb}$-only blank, the $\mathrm{NaI}(+\mathrm{Nb})$ blank and an $\mathrm{AgI}(+\mathrm{Nb})$ reference. The $\mathrm{Nb}$ used is the Alfa Aesar -325 mesh Puratronic powder, the NaI blank is the pure ${ }^{127}$ I-carrier material used at IsoTrace and at the Lalonde AMS for processing AgI samples. The AgI reference is a locally prepared standard (diluted from NIST-4949C using the NaI blank and calibrated against NIST-3230-I\&II to have ${ }^{129} \mathrm{I} /{ }^{127} \mathrm{I}=$ $\left.(1.305 \pm 0.018) \times 10^{-11}\right)$. Figure 3 summarizes these results: (1) the measured ${ }^{129} \mathrm{I} /{ }^{127} \mathrm{I}$ ratio of the $6 \mathrm{NaI}$ blanks, with and without the Nb-only blank correction applied, and (2) the averaged block sequences of the ${ }^{129} \mathrm{I}^{+2}$ counts and ${ }^{127} \mathrm{I}^{+2}$ current from the 6 pure Nb-only blanks. The Nb-only blank corrected results refer to those obtained after subtracting the average ${ }^{129} \mathrm{I}$ count and ${ }^{127} \mathrm{I}$ current from the Nb-only blanks included in the same batch.

The lowest possible $\mathrm{Cs}^{+}$flux refers to the Cs reservoir being air cooled and no heating applied. The next two $\mathrm{Cs}^{+}$fluxes were obtained with air cooling stopped and with the Cs reservoir heated to $85^{\circ} \mathrm{C}$ and $105^{\circ} \mathrm{C}$, respectively. As can be seen by the average ${ }^{127} \mathrm{I}^{+2}$ current from the $\mathrm{NaI}$ and $\mathrm{AgI}$ targets, even the highest $\mathrm{Cs}^{+}$flux used can be considered as very modest, but the recycled ${ }^{129} \mathrm{I}^{+2}$ count rates and ${ }^{127} \mathrm{I}^{+2}$ currents, as indicated by the pure Nb-only blanks, are clearly measured. The highest $\mathrm{Cs}^{+}$flux used in this test is estimated to be only 
Lowest possible $\mathrm{Cs}^{+}$flux

(ave. $\left.{ }^{127}\right|^{* 2} \sim 0.22 \mu \mathrm{A}$ )
Low $\mathrm{Cs}^{+}$flux

(ave. $12 / I^{* 2} \sim 1.6 \mu \mathrm{A}$ )
Modest Cs $^{+}$flux

(ave. ${ }^{12} / \cdot 2 \sim 3.3 \mu \mathrm{A}$ )

Results of ${ }^{129}\left|/^{127}\right|\left(\times 10^{-14}\right)$ of 6 Nal blank targets

\begin{tabular}{|c|c|c|c|c|c|c|c|c|}
\hline$\frac{\text { Target }}{\# 1}$ & $\frac{w / o ~ N b-c o r}{0.7 \pm 0.1}$ & $\frac{\text { with Nb-cor }}{0.4 \pm 0.1}$ & $\frac{\text { Target }}{\# 1}$ & $\frac{w / o ~ N b-c o r}{1.1 \pm 0.1}$ & $\frac{\text { with } \mathrm{Nb} \text {-cor }}{1.0 \pm 0.1}$ & $\frac{\text { Target }}{\# 1}$ & $\frac{w / o ~ N b-c o r}{1.5 \pm 0.1}$ & $\frac{\text { with Nb-cor }}{1.2 \pm 0.1}$ \\
\hline$\# 2$ & $0.9 \pm 0.2$ & $0.5 \pm 0.1$ & $\# 2$ & $1.3 \pm 0.1$ & $1.2 \pm 0.1$ & $\# 2$ & $1.8+0.1$ & $1.3+0.1$ \\
\hline$\# 3$ & $0.9 \pm 0.2$ & $0.5 \pm 0.1$ & $\# 3$ & $1.1 \pm 0.1$ & $1.0 \pm 0.1$ & $\# 3$ & $1.5 \pm 0.1$ & $1.2 \pm 0.1$ \\
\hline$\# 4$ & $0.8 \pm 0.2$ & $0.4 \pm 0.1$ & $\# 4$ & $1.2 \pm 0.1$ & $1.1 \pm 0.1$ & $\# 4$ & $1.6 \pm 0.1$ & $1.2 \pm 0.1$ \\
\hline$\# 5$ & $0.5 \pm 0.1$ & $0.2 \pm 0.1$ & $\# 5$ & $1.0 \pm 0.1$ & $0.9 \pm 0.1$ & $\# 5$ & $1.3 \pm 0.1$ & $1.0=0.1$ \\
\hline$\# 6$ & $0.6 \pm 0.1$ & $0.3 \pm 0.1$ & $\# 6$ & $0.9 \pm 0.1$ & $0.8 \pm 0.1$ & $\# 6$ & $1.3+0.1$ & $1.0+0.1$ \\
\hline W.A. & $0.65 \pm 0.06$ & $0.38 \pm 0.05$ & W.A. & $1.10 \pm 0.06$ & $1.00 \pm 0.06$ & W.A. & $1.50 \pm 0.08$ & $1.15 \pm 0.05$ \\
\hline
\end{tabular}

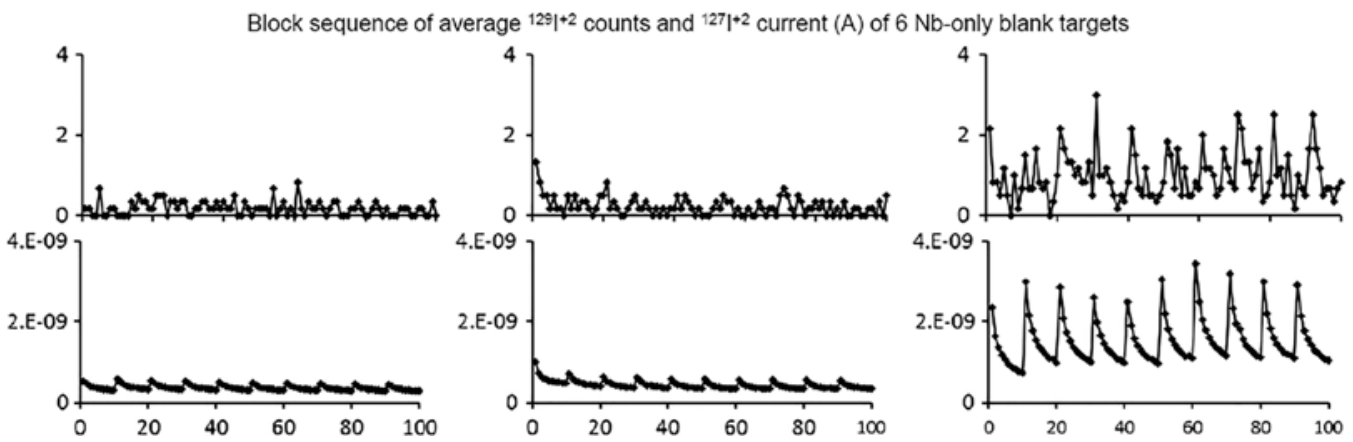

Figure 3 Comparison of $\mathrm{NaI}$ blank measurement under 3 different $\mathrm{Cs}^{+}$flux conditions; all done using $92 \mathrm{~Hz}$ fast sequential injection, 30 second per block of measurement, 10 blocks per pass and 10 passes in total for all targets.

about $10 \%$ of the $\leq 0.3 \mathrm{~mA}$ used for ${ }^{14} \mathrm{C}$ runs. These are truly very modest $\mathrm{Cs}^{+}$fluxes by today's standard of the Middleton-type sputter sources. These modest $\mathrm{Cs}^{+}$fluxes are expected to make only minor differences to the focused $\mathrm{Cs}^{+}$spot on the target by space charges. With the highest $\mathrm{Cs}^{+}$flux used in this test, the average ${ }^{127} \mathrm{I}^{+2}$ current from the NaI and AgI targets, which contain $\sim 1 \mathrm{mg}$ iodine each, is $\sim 3.3 \mu \mathrm{A}$, but the iodine-free $\mathrm{Nb}$-only blanks give $1-3 \mathrm{nA}$ on average. Considering the purity of this $\mathrm{Nb}$ material, the 1-3 nA current, with its sawtooth character upon inserting an $\mathrm{Nb}$-only blank for each measurement pass following an $\mathrm{AgI}(+\mathrm{Nb})$ reference, must be mainly due to the ion source memory effects. Therefore, the measurement of very-low level ${ }^{129} \mathrm{I}$ samples requires a low $\mathrm{Cs}^{+}$flux where the results must be corrected for the ion source generated background as estimated by the binder-only blanks. The NaI blank material used here could very well be truly ${ }^{129}$ I-free. However, to make a measurement to yield the lowest possible ${ }^{129} \mathrm{I} /{ }^{127} \mathrm{I}$ ratio while interleaving with the reference targets of ${ }^{129} \mathrm{I} /{ }^{127} \mathrm{I} \sim 1.3 \times 10^{-11}$, it seems that almost no thermal heating $\mathrm{Cs}^{+}$flux can be used. At present, the routine ${ }^{129} \mathrm{I}$ measurements in this laboratory use a low $\mathrm{Cs}^{+}$flux (not necessarily always corresponding to the same Cs reservoir temperature) that produces $\leq 2 \mu \mathrm{A}{ }^{127} \mathrm{I}^{+2}$ current from the $\mathrm{NaI}$ and AgI targets, and the results are always corrected by the Nb-only blanks. For measuring geological ${ }^{129}$ I samples, the lowest possible $\mathrm{Cs}^{+}$flux is used. Similar cautions are necessary whenever sample materials are similarly volatile.

\section{BLANK-LEVEL BATCH RUNS WITH NO MODERN REFERENCES}

The above experiment reveals a practical dilemma when it comes to the measurement of very-low level samples. On the one hand, the use of high $\mathrm{Cs}^{+}$fluxes is required to obtain appreciable counting statistics quickly enough; on the other hand, the use of a low $\mathrm{Cs}^{+}$flux is needed to obtain results that are close to being accurate. For more volatile sample 


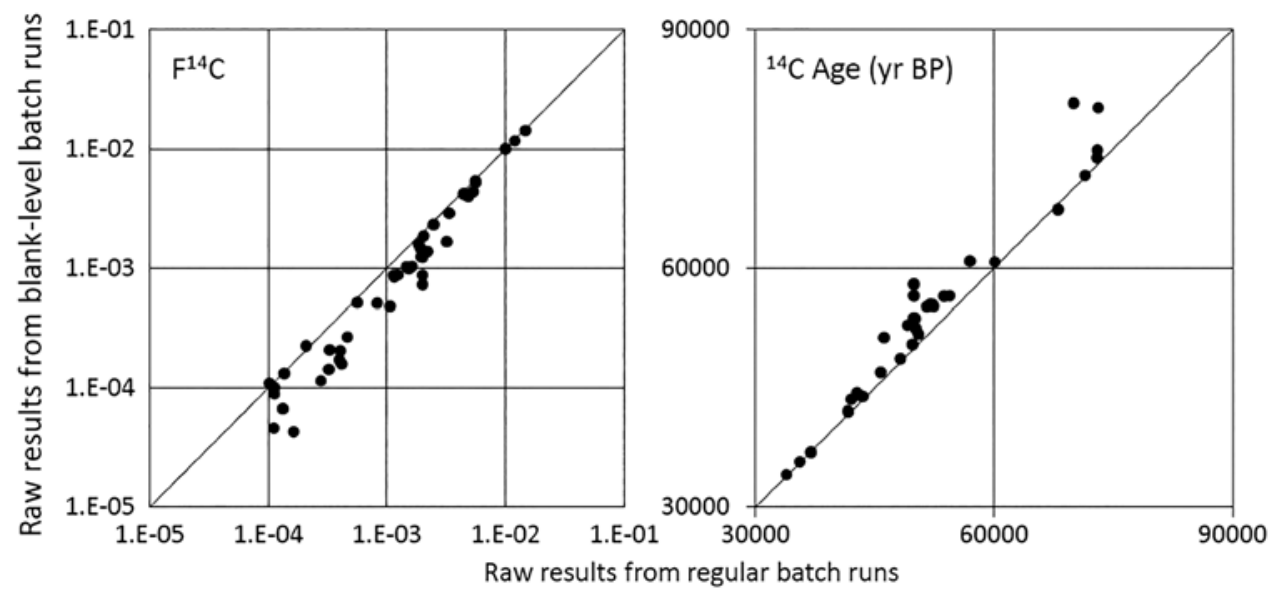

Figure 4 Raw results comparing of the same process blank targets measured during the regular batch runs and the blank-level batch runs performed before or after. Several different blank materials are included, involving different methods for pretreatment (Crann et al. 2017), both Elemental Analyzer (EA) and hydrolysis (for IAEA-C1) for $\mathrm{CO}_{2}$ production.

materials there may be little choice but to limit the intensities of the $\mathrm{Cs}^{+}$sputter beam, whereas for the less volatile sample materials such as graphite, it is more appropriate to explore other means of minimizing the ion source memory effects while still using high $\mathrm{Cs}^{+}$fluxes as for typical routine runs.

As discussed earlier, a possible cause of these enhanced memory effects is the disturbances of the CSSIT. It is frequently evident that, as a batch run progresses, the memory effects tend to decrease. This is likely due to the completion of out-gassing from all the targets by $\mathrm{Cs}^{+}$ sputtering, and also the conditioning of the CSSIT when the vigorous deposition and reemission of contaminating materials has reduced to a lower equilibrium level. Thus, if a batch of ${ }^{14} \mathrm{C}$ samples are measured after a prolonged period of $\mathrm{Cs}^{+}$sputtering, the old samples tend to yield somewhat older ages. Such effect should be even more pronounced if, after sufficient conditioning, no higher-level material (including standards) is sputtered in the ion source, so that the source of higher-level memory is avoided and the batch run proceeds with the background-level samples only. Such ability of yielding older ages has been readily observed on several occasions. In the first case, after a regular batch run was completed, the process blanks contained in the batch were measured under the same AMS conditions again, without interleafing with any other non-blank targets. The results were normalized to the Ox-II targets measured earlier in the regular batch run. In the second case, a new batch of samples was installed after the ion source had been operated on $\mathrm{PbF}_{2}$-based targets for a week. Some selected process blanks were first measured in a blank-level batch run with the AMS tuned and magnetic fields scaled using a ${ }^{14} \mathrm{C}$-free graphite. The results were normalized to Ox-II targets measured afterwards under the same AMS conditions. These selected blanks were then measured again within the regular batch run that followed.

Figure 4 presents a comparison of the raw results of the process blank targets chosen for the test, obtained from both the regular batch runs that included many high-level references and samples, and the special blank-level batch runs performed either before or after the related regular batch run. Note that these two different sets of results were all from 
the same targets installed in the sampling wheel; the two panels in Figure 4 are for the same comparison, one plotted in $\mathrm{F}^{14} \mathrm{C}$ and the other in ${ }^{14} \mathrm{C}$ age. As expected, the special blank-level batch runs tend to push back the ${ }^{14} \mathrm{C}$ ages noticeably.

The above tests with ${ }^{129} \mathrm{I}$ and ${ }^{14} \mathrm{C}$ blanks all suggest that the background counts, resulting from the ion source memory effects, could contribute significantly in addition to the contamination introduced during sample preparation steps. For the purpose of assessing the possible ${ }^{14} \mathrm{C}$-dead organic materials, the ion source generated background must be minimized as much as possible. From the understanding above, this would first require that the CSSIT to be prepared as pristinely as possible, followed by no introduction of elevated levels of ${ }^{14} \mathrm{C}$ into this critical region during the analysis, thus avoiding the "memory" issue. A thorough ionsource cleaning is obviously the first step. However, a normal source cleaning alone may still not be enough. It has been causally experienced that obtaining pristine surface conditions appear to be more probable if the source is first operated for a few days with $\mathrm{PbF}_{2}$-based targets. A speculation is that the reactive vapors released from such targets provide a mild surface etching or an in-situ deep cleaning. The blank-level batch runs are therefore best done following not only a source cleaning, but also an initial operation on $\mathrm{PbF}_{2}$-based targets without ever sputtering a ${ }^{14} \mathrm{C}$-containing target. (However, including $\mathrm{PbF}_{2}$ targets within batch runs for periodic source cleaning purposes may cause undesirable varying fractionation, and has thus not been considered.) The results of such low-level samples can be normalized to Ox-II standard targets measured under the same AMS conditions in a following batch run.

To do with the above procedure the AMS system must be tuned using a ${ }^{14} \mathrm{C}$-free graphite target. In our case an Alfa Aesar graphite target (AA-Graphite) is pressed without mixing with $\mathrm{Fe}$ powder. (So far, the total number of ${ }^{14} \mathrm{C}$ counts received from a Fe-only blank target always exceeds that from a pure AA-graphite target.) The ${ }^{13} \mathrm{C}^{-}$beam from an AAGraphite can be used to tune the AMS system and scale the magnetic fields despite the imperfections of tuning without counting ${ }^{14} \mathrm{C}^{+3}$ ions directly. Whatever the tuning quality $\left({ }^{14} \mathrm{C}^{+3}\right.$ ions may not be counted fully), the standard targets must subsequently be measured under the same conditions, assuming that the AMS system has a sufficient long-lasting stability (as has been found to be the case with the Lalonde AMS system). Such blank-level batch runs have been experimented several times. For these measurements, up to 20 initial blocks of data are always discarded to sufficiently exclude the target surface contaminations. However, the remaining background would still depend upon the unpredictable details of the final ion source surface conditions and the potentially already incorporated contamination prior to graphitization. So far, these measurements have always yielded somewhat older than usual ages for the blanks (Figure 4). In a few rare cases (Table 1), some extremely old ages were attained. The Fe-only blank corrected results refer to those obtained after subtracting the average ${ }^{14} \mathrm{C}$ count and ${ }^{13,12} \mathrm{C}$ currents from the Fe-only blanks included in the same batch. The Alfa Aesar graphite is at best measured to $\geq 85 \mathrm{kyr} \mathrm{BP}$ in these cases. When the same material is measured within the regular ${ }^{14} \mathrm{C}$ batch runs, the results have been mostly in the range of $60-70 \mathrm{kyr} \mathrm{BP}$.

\section{STUDIES WITH DIRECTLY MEASURABLE, NATURALLY OCCURRING BLANK MATERIALS}

The $\geq 85 \mathrm{kyr}$ age for the Alfa Aesar graphite is not too surprising, as special measurement on natural diamonds have also yielded similarly old ages (Taylor and Southon 2007) where neither the Alfa Aesar graphite nor the natural diamonds required any chemical 
Table 1 Results of two more satisfactory blank-level batch runs.

\begin{tabular}{|c|c|c|c|c|c|c|c|c|}
\hline \multirow[b]{2}{*}{ Run } & \multirow[b]{2}{*}{ UOC-\# } & \multirow[b]{2}{*}{$\begin{array}{c}\text { Blank/sample } \\
\text { material }\end{array}$} & \multirow[b]{2}{*}{$\begin{array}{l}\text { Pre- } \\
\text { treatment }\end{array}$} & \multirow[b]{2}{*}{$\begin{array}{l}\text { Combustion } \\
\text { method }\end{array}$} & \multicolumn{2}{|c|}{ Average beam } & \multicolumn{2}{|c|}{${ }^{14} \mathrm{C}$ age (yr BP) } \\
\hline & & & & & $\begin{array}{c}{ }^{14} \mathrm{C}^{+3} \text { (counts } \\
\text { / blocks) }\end{array}$ & ${ }^{12} \mathrm{C}^{+3}(\mu \mathrm{A})$ & Raw results & Fe-blk cor'd. \\
\hline \multirow[t]{7}{*}{1} & \multicolumn{2}{|c|}{ Alfa Aesar graphite } & No & No & $14 / 210$ & 15.4 & $85100 \pm 3600$ & \\
\hline & & & & & $13 / 210$ & 14.6 & $85400 \pm 3700$ & \\
\hline & \multirow{2}{*}{\multicolumn{2}{|c|}{ Fe-only blanks }} & No & No & $30 / 205$ & 0.018 & & \\
\hline & & & & & $29 / 205$ & 0.012 & & \\
\hline & 3810 & \multirow{3}{*}{ Acetanilide } & No & Qtz-9mm I.D. & $68 / 205$ & 22.1 & $73600 \pm 1800$ & $77300 \pm 2500$ \\
\hline & 3822 & & & Qtz-6mm I.D. & $48 / 205$ & 24.3 & $78900 \pm 2100$ & $86200 \pm 2300$ \\
\hline & 3833 & & & EA & $43 / 205$ & 14.3 & $75600 \pm 2200$ & $84500 \pm 2400$ \\
\hline \multirow[t]{12}{*}{2} & \multirow{6}{*}{\multicolumn{2}{|c|}{ Fe-only blanks }} & No & No & $32 / 110$ & 0.006 & & \\
\hline & & & & & $33 / 110$ & 0.011 & & \\
\hline & & & & & $33 / 110$ & 0.006 & & \\
\hline & & & & & $34 / 110$ & 0.015 & & \\
\hline & & & & & $35 / 110$ & 0.016 & & \\
\hline & & & & & $30 / 110$ & 0.013 & & \\
\hline & 3147 & \multirow[t]{2}{*}{ Acetanilide } & \multirow[t]{2}{*}{ No } & \multirow[t]{2}{*}{ EA } & $53 / 110$ & 16.8 & $68100 \pm 2200$ & $75800 \pm 2500$ \\
\hline & 3148 & & & & $17 / 110$ & 45.6 & $87200 \pm 3300$ & $>90000$ \\
\hline & 3149 & \multirow[t]{2}{*}{ Acetanilide } & \multirow[t]{2}{*}{ No } & \multirow[t]{2}{*}{ Qtz-6mm I.D. } & $21 / 110$ & 24.9 & $80700 \pm 3000$ & $>90000$ \\
\hline & 3150 & & & & $21 / 110$ & 40.8 & $85600 \pm 3500$ & $>90000$ \\
\hline & 3341 & $\begin{array}{c}\text { DDA amine } \\
\text { SNO+ sample } 1\end{array}$ & No & EA & $48 / 100$ & 17.8 & $69800 \pm 1900$ & $80000 \pm 2400$ \\
\hline & 3342 & $\begin{array}{c}\text { DDA amine } \\
\text { SNO+ sample } 2\end{array}$ & & & $62 / 110$ & 43.0 & $74000 \pm 1800$ & $80700 \pm 2300$ \\
\hline
\end{tabular}


processing or binder mixing. The unusual results have been the $\geq 70 \mathrm{kyr}$ ages for the blanks and samples that went through $\mathrm{CO}_{2}$ production by combustion (EA/Quartz) or hydrolysis (for IAEA-C1) and were graphitized; even though they did not require much pretreatment. In other words, these later sample processing steps do not seem to prevent AMS ${ }^{14} \mathrm{C}$ dating beyond the usual $60 \mathrm{kyr}$ limit. This appears at odds with common consensus that contamination introduced in sample processing always determines the measurement limit. Although more studies are needed, it is at least very clear that the results of very old samples would also depend upon the details of the measurement procedures and the ion source surface conditions.

Old ${ }^{14} \mathrm{C}$ results are known to be difficult to reproduce (Scott et al. 2017a, 2017b). Part of the reason could be that the ion source surface conditions are difficult to reproduce. In the case of the SO-110B ion source (Kieser et al. 2015), the ionizer shroud is one of the most difficult pieces to restore to its pristine surface condition, unless a brand-new shroud is used during each source cleaning. The ionizer surface condition is also hard to restore; aggressive cleaning has yet to be attempted in this laboratory. Furthermore, even if all critical surfaces can be restored to pristine conditions during every source cleaning, the subsequent usage may vary depending on what types of samples and how many targets have been sputtered. Also, the interactions between the sputtered neutral particles and the ionizer/CSSIT could vary with respect to target emission details, such as types of particles, rates, angular distributions, etc. Finally, different target materials must also have different properties for acting as catalyst when receiving carbon-containing molecules (or iodinecontaining materials in the case of ${ }^{129} \mathrm{I}$ measurements). These arguments would imply that the direct measurement of a Fe-free commercial Alfa Aesar graphite target to a $>60 \mathrm{kyr}$ age, does not mean that all the ion source generated background from the Fe-containing graphite samples is also at the same level. This can also be seen in the case of ${ }^{129} \mathrm{I}$ measurements where Ag-only blanks always tend to yield several times more background iodine beams than Nb-only blanks, which is not too surprising given the difference between $\mathrm{Ag}$ and $\mathrm{Nb}$ chemistry for reacting with iodine. In fact, such conclusions are hardly difficult to imagine considering that so much carbon (possibly over $10 \mathrm{mg}$ after sputtering off 200 targets containing $\sim 1 \mathrm{mgC}$ each) inevitably ends up depositing onto the ionizer/CSSIT during batch runs. (Such effects may be lessened with recessed targets by collimating neutrals into reduced solid angle ejection.) These surfaces are far more contaminated than any others involved in sample preparation steps after pretreatment. How these "dirty" surfaces are disturbed and interact with sample materials in a target during measurement must have a direct impact in the measured carbon ages of old samples. The effects begin to be observed for samples $\geq 45 \mathrm{kyr}$ as shown in Figure 4 . Clearly, reporting maximum ages is difficult as contamination in sample processing is no longer the only concern.

To further understand the relative importance of contamination by sample chemistry and by the ion source, suitable blank materials that can be directly measured without sample chemistry are very useful. Table 2 presents the results of one such study and shows that sometimes the ion source oriented background could indeed be more significant. In this particular example, a charcoal sample kindly provided by Dr. Jesper Olsen at Aarhus AMS was measured through the routine steps of AAA pretreatment, EA combustion and graphitization to be 55 57 kyr BP by the raw data. The same material was then measured directly in blanklevel batch runs (even without the ion source cleaned or $\mathrm{PbF}_{2}$-conditioned) to be $\sim 80 \mathrm{kyr}$ $\mathrm{BP}$, also by the raw data. A heavy element survey on proliferate fluoride negative ions was 
Table 2 (Continued)

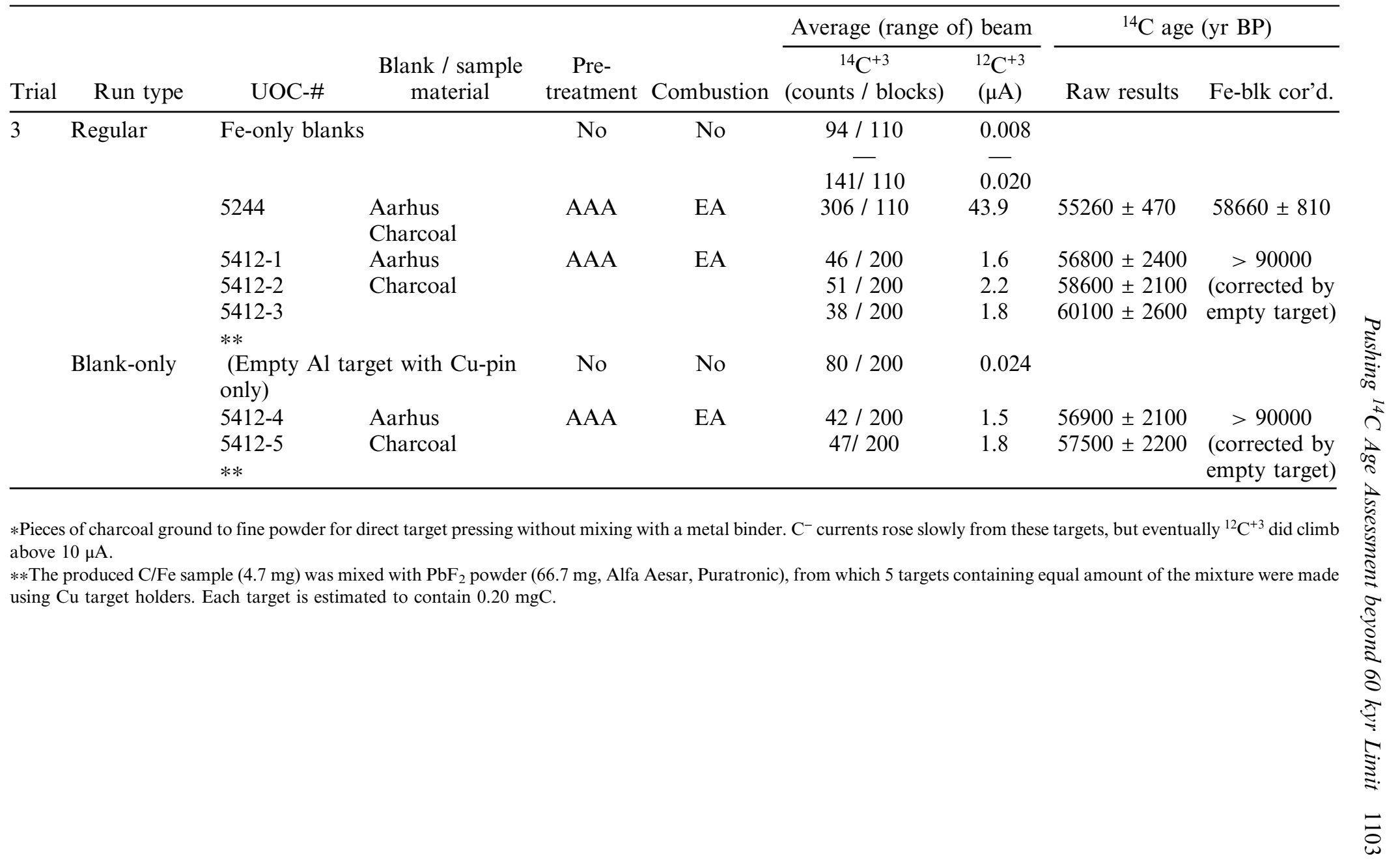


also carried out with targets made of mixtures of pure $\mathrm{PbF}_{2}$ powder and the powder ground from this charcoal. A quick search for isotopes from $\mathrm{Ra}$ to $\mathrm{Pu}$ suggests that ${ }^{226} \mathrm{Ra},{ }^{230} \mathrm{Th}$, and ${ }^{234} \mathrm{U}$ are present in this charcoal in amounts far exceeding those of the $\mathrm{PbF}_{2}$-only blanks. The clear presence of ${ }^{230} \mathrm{Th}$ suggests that this charcoal is likely older beyond the ${ }^{14} \mathrm{C}$ dating range (although the crudely estimated ratios of ${ }^{230} \mathrm{Th} /{ }^{234} \mathrm{U} \sim 0.011$ and ${ }^{226} \mathrm{Ra} /{ }^{230} \mathrm{Th} \sim 0.26$ do not correspond to secular equilibrium, possibly due to the charcoal being an open system). The directly measured ${ }^{14} \mathrm{C}$ age of $\sim 80 \mathrm{kyr}$ BP is likely due to the very limit of the ion source generated ${ }^{14} \mathrm{C}$ dark count rates versus the smaller carbon beams that can be produced from the straight pressed charcoal targets.

Accepting $\geq 80 \mathrm{kyr}$ BP as the charcoal's true age, it can be seen that the effectiveness of the Feonly blank corrections varies considerably from one batch run to another. Although the practice requires further investigation, the Fe-only blank corrected results reveal enough to suggest that, at least for this particular charcoal sample, the preparation steps could not have been the main source of contamination by comparison with that already collected within the ion source during the regular batch runs. Indeed, the use of Fe-only blanks for estimating the amount of ion source generated background serves a useful purpose in this particular case.

However, Fe, being a catalyst, also makes it difficult to differentiate between the relative contributions from the two different processes: (1) catalytic reduction of carbon from hydrocarbons in the vacuum, and (2) the recycled sputtering of carbon containing materials accumulated on the ionizer/CSSIT from previously sputtered targets. This is also briefly investigated. Instead of removing $\mathrm{Fe}$ from $\mathrm{C}$, the catalytic reactivity of $\mathrm{Fe}$ can be effectively prohibited by mixing the $\mathrm{C} / \mathrm{Fe}$ sample material with an excessive amount of $\mathrm{PbF}_{2}$. The fluorinating reactions should rapidly oxidize $\mathrm{Fe}$ to its highest oxidization state and disable its function as a catalyst. A normally processed graphite sample of the Aarhus Charcoal was mixed with an excessive amount of $\mathrm{PbF}_{2}$ and pressed into five targets, each containing about $0.20 \mathrm{mgC}$ (see Table 2). Three were measured within a regular batch run containing many targets at contemporary levels, and two were afterward measured alone, together with an empty $\mathrm{Al}$ target holder pressed only with a $\mathrm{Cu}$ pin. The number of ${ }^{14} \mathrm{C}^{+3}$ counts from the $\mathrm{PbF}_{2}$ composite targets, measured in both the regular batch run and the blank-only run afterward, was observed to be considerably fewer than those from the Feonly blanks and even the empty target holder. Clearly, the added $\mathrm{PbF}_{2}$ had a major effect on reducing the background ${ }^{14} \mathrm{C}^{+3}$ counts where the reasons may be complicated and require further studies to clarify. Unfortunately, the carbon beams were also reduced considerably from these $\mathrm{PbF}_{2}$ composite targets, the measured raw ages (57 60 kyr BP) were only slightly older than those from the regular graphite targets measured in the routine batch runs. However, if the empty target holder was used as the actual machine blank to correct the background for the $\mathrm{PbF}_{2}$ composite targets, the resulting (infinite) ages led to the same indication that the sample processing steps which involved AAA pretreatment, EA combustion and graphitization, did not introduce sufficient contamination to prevent ${ }^{14} \mathrm{C}$ dating up to $80 \mathrm{kyr}$. As far as this particular sample is concerned, the background originating within the ion source appears to be the dominant one. Unfortunately, this brief experiment attempting to distinguish the final background sources, catalysis or recycled sputtering, was unsuccessful. The question on the relative background contribution by $\mathrm{Fe}$ being a catalyst in the target is still unanswered and will need to be further studied. 


\section{DISCUSSION AND OUTLOOK}

The sum of these background studies indicates the following:

1. the present-day standard $\mathrm{Cs}^{+}$sputter ion source, with the hot ionizer directly facing the catalyst-containing graphite target in a tightly coupled structure, is not yet ideal for AMS to reach its ultimate potential sensitivity; and

2. the use of catalyst-only (or binder-only) blanks to track and to correct this ion source generated background, is useful for measuring very-low level samples, even though the effects of such correction have not always been sufficient.

To reach the ultimate goals of the OCP, the development of AMS equipment has certainly gone a long way in bringing tremendous sensitivity to atom counting as has been demonstrated using the $3 \mathrm{MV}$ system at Lalonde AMS. The frontier is now in the elimination of the ion source generated background. Ultimately, new ion sources that are optimized for AMS need to be developed, even though this is less critical for ${ }^{14} \mathrm{C}$ as for others that use more volatile sample materials. Possible new design goals may include (1) making the first target aperture part of the target itself, to retain most sputtered neutrals within each target's own containment volume (e.g. Pavetich et al. 2014); (2) avoiding direct line-of-sight between the sample material and the ionizer/CSSIT; and (3) providing effective sinks for vapors released from samples.

In summary, it has been shown that the ion-source memory effects may at times exceed sample processing contamination to become the final barrier to the measurement of very-low level samples. By operating the present-day standard $\mathrm{Cs}^{+}$sputter ion source in ways which reduce or avoid the memory effects, the sensitivity of an existing AMS system and sample processing method can be improved. With the precautions learned in this study and the use of catalyst/ binder-only blanks to track and partially correct the ion source generated background, an ${ }^{129} \mathrm{I} /{ }^{127} \mathrm{I} \sim 1 \times 10^{-14}$ result from our (possibly ${ }^{129} \mathrm{I}$-free) NaI blank is achieved for routine measurements. For old ${ }^{14} \mathrm{C}$ samples, age assessments beyond $60 \mathrm{kyr}$ are possible when they are not prevented by contamination before and during sample preparation. The study also suggests that if the present-day standard $\mathrm{Cs}^{+}$sputter source is redeveloped to eliminate the recycling of sputtered materials, the second promise of the AMS pioneers-extending the ${ }^{14} \mathrm{C}$ dating range to beyond the long-standing $60 \mathrm{kyr}$ limit, could be more readily realized.

\section{ACKNOWLEDGMENTS}

Financial support from CFI, ORF, CSS and NSERC are gratefully acknowledged. We would like to thank Prof. Ted Litherland for his simulating discussions on the OCP topic since the early 2000s. We are grateful to Dr. Jesper Olsen at Aarhus AMS for providing us the $\geq 80 \mathrm{kyr}$ old charcoal sample suitable for direct AMS measurement without sample chemistry, and also to all the reviewers of this manuscript for their in-depth comments and extensive discussions.

\section{REFERENCES}

Andringa S, et al. 2016. Current status and future prospect of $\mathrm{SNO}+$ experiment. Advances in High Energy Physica 2016:1-21.

Beukens RP. 1993. Radiocarbon accelerator mass spectrometry: background and contamination. Nuclear Instruments and Methods in Physics Research B 79:620-623.
Beukens RP, Gove HE, Litherland AE, Kieser WE, Zhao X-L. 2004. The old carbon project: how old is old? Nuclear Instruments and Methods in Physics Research B 223-224:333-338.

Crann CA, Murseli S, St.-Jean D, Zhao X-L, Kieser WE, Clark ID. 2017. First status report on radiocarbon sample preparation techniques at 
the A. E. Lalonde AMS Laboratory (Ottawa, Canada). Radiocarbon 59(3):695-704.

Kieser WE, Zhao X-L, Clark ID, Cornett RJ, Litherland AE, Klein M, Mous DJW, Alary J-F. 2015. The André E. Lalonde AMS Laboratorythe new accelerator mass spectrometry facility at the University of Ottawa. Nuclear Instruments and Methods in Physics Research B 361:110-114.

Litherland AE, Gove HE, Beukens RP, Zhao X-L, Kieser WE. 2005. Low-level ${ }^{14} \mathrm{C}$ measurements and accelerator mass spectrometry. In: Cleveland B, Ford R, Chen M, editors. Topical Workshop on Low Radioactivity Techniques. American Institute of Physics CP 785:48-56.

Middleton R, Klein J. 1997. Carbon anions and dianion clusters. Nuclear Instruments and Methods in Physics Research B 123:532-538.

Paul D, Been HA, Aerts-Bijma AT, Meijer HAJ. 2016. Contamination on AMS sample targets by modern carbon is inevitable. Radiocarbon 58(2):407-418.

Pavetich S, Akhmadaliev S, Arnold M, Aumaître G, Bourlès D, Buchriegler J, Golser R, Keddadouche K, Martschini M, Merchel S, Rugel G, Steir P. 2014. Interlaboratory study of the ion source memory effect in ${ }^{36} \mathrm{Cl}$ accelerator mass spectrometry. Nuclear Instruments and Methods in Physics Research B 329:22-29.

Santos GM, Mazon M, Southon JR, Rifai S, Moore R. 2007. Evaluation of iron and cobalt powders as catalysts for ${ }^{14} \mathrm{C}$-AMS target preparation. Nuclear Instruments and Methods in Physics Research B 259:308-315.

Schmidt FH, Balsley DR, Leach DD. 1987. Early expectations of AMS: greater ages and tiny fractions. One failure?- One success. Nuclear Instruments and Methods in Physics Research B 29:97-99.

Scott EM, Naysmith P, Cook GT. 2017a. Why do we need ${ }^{14} \mathrm{C}$ inter-comparisons? The Glasgow ${ }^{14} \mathrm{C}$ inter-comparison series, a reflection over 30 years. Quaternary Geochronology 43:72-82.

Scott EM, Naysmith P, Cook GT. 2017b. Should archaeologists care about ${ }^{14} \mathrm{C}$ inter-comparisons? Why? A summary report on SIRI. Radiocarbon 59(5):1589-1596

Taylor RE, Southon J. 2007. Use of natural diamonds to monitor ${ }^{14} \mathrm{C}$ AMS instrument backgrounds. Nuclear Instruments and Methods in Physics Research B 259:282-287.

Vockenhuber C, Casacuberta N, Christl M, Synal HA. 2015. Accelerator mass spectrometry of ${ }^{129} \mathrm{I}$ towards its lower limits. Nuclear Instruments and Methods in Physics Research B 361:445-449.

Zhao X-L, Charles CRJ, Cornett RJ, Kieser WE, MacDonald C, Kazi Z, St.-Jean N. 2016. An exploratory study of recycled sputtering and $\mathrm{CsF}_{2}^{-}$current enhancement for AMS. Nuclear Instruments and Methods in Physics Research B 366:96-103. 